\title{
Tornado Generation in a Narrow Cold Frontal Rainband - Fujisawa Tornado on April 20, 2006-
}

\author{
Fumiaki Kobayashi ${ }^{1}$, Yuya Sugawara ${ }^{1}$, Maki Imai $^{1}$, Masahiro Matsui², \\ Akihito Yoshida ${ }^{2}$ and Yukio Tamura ${ }^{2}$ \\ ${ }^{1}$ National Defense Academy, Yokosuka, Japan \\ ${ }^{2}$ Tokyo Polytechnic University, Atsugi, Japan
}

\begin{abstract}
At noon on April 20, 2006, a wind storm occurred in Fujisawa City, Kanagawa Prefecture, Japan with a F0P1-P1 rank on the Fujita-Pearson-scale (FPP-scale). Damage to over 40 residential buildings was observed. The damage covered an area $2 \mathrm{~km}$ by $50 \mathrm{~m}$. The strong winds were accompanied by the passage of a cold front. Eyewitness accounts of a dust column and the recording of a pressure drop $(1.5 \mathrm{hPa})$ indicate the existence of a tornado vortex. A hook-shaped radar echo $(5 \mathrm{~km}$ in diameter) was observed in the narrow cold frontal rainband, with strong horizontal wind shear above the damage area. The Doppler velocity pattern indicated a misocyclone, which had a diameter of $2 \mathrm{~km}$ and a vorticity on the order of $10^{-2} \mathrm{~s}^{-1}$. The wind storm may have caused the tornado, which formed in the cold frontal wind shear zone.
\end{abstract}

\section{Introduction}

In Japan, tornadoes and tornado-related disasters can occur all year round. Tornadoes are also commonly accompanied by extratropical cyclones, typhoons and heat thunderstorms. Supercell tornadoes that accompany mesocyclones in the parent cloud are often reported in Japan (e.g., Niino et al. 1993; Kobayashi et al. 1996). Suzuki et al. (2000) described a supercell type (mini-supercell) tornado within the rainband of a typhoon. Many waterspouts (non-supercell tornadoes) have occurred near the coastline of Japan (e.g., Kobayashi et al. 1997). Although many tornadoes were accompanied by a developing synoptic low or cold front (Niino et al. 1997), the mechanism and structure of tornadoes that occurred in the cold frontal rainband have been unsolved until now.

At noon on April 20, 2006, a wind storm occurred in Fujisawa City, Kanagawa (Tokyo District Meteorological Observatory 2006). A tornado caused damage to over 40 residential buildings. Doppler radar observation was carried out at Yokosuka, near Fujisawa during the passage of the cold front. In this paper, we document the tornado, which was generated in the narrow cold frontal rainband.

\section{Synoptic situation}

The weather map at 12:00 JST (Japan Standard Time) on April 20, 2006 shows a cold front extending from the $992 \mathrm{hPa}$ low to the Pacific Ocean (Fig. 1). This implies that the synoptic low moved slowly towards the

Corresponding author: Fumiaki Kobayashi, Department of Geoscience, National Defense Academy, Hashirimizu, Yokosuka 239-8686, Japan. E-mail: kobayasi@nda.ac.jp. @2007, the Meteorological Society of Japan.

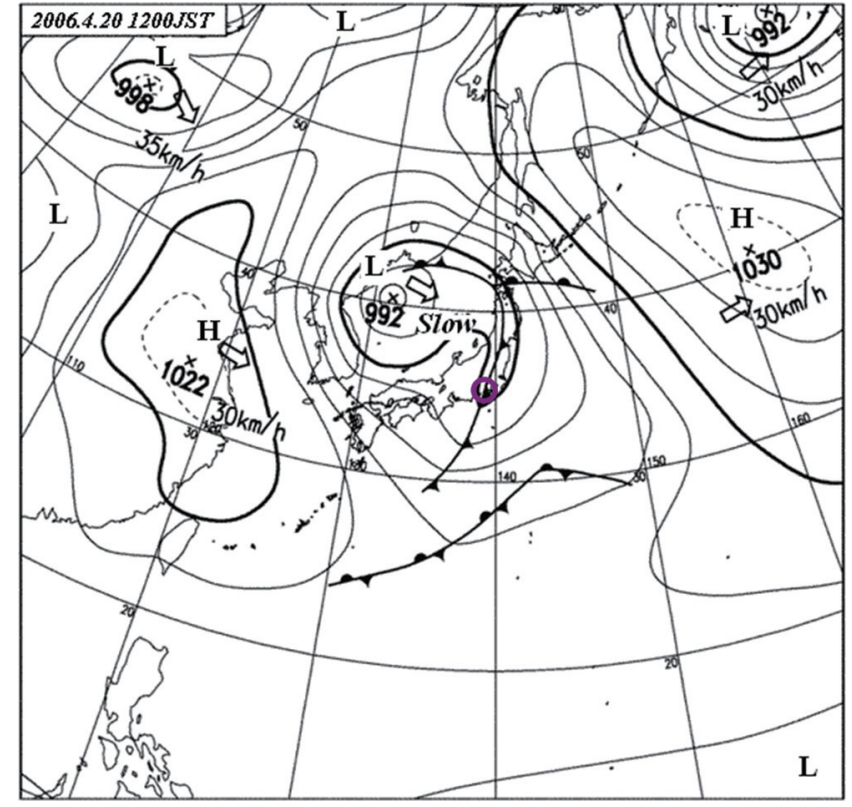

Fig. 1. Surface weather map at 12:00 JST on April 20, 2006. A circle denotes the location of Fujisawa City.

southeast as the cold front passed over Fujisawa City, Kanagawa Prefecture. Figure 2 shows the geostationary meteorological satellite (GMS) MTSAT-1R infrared image at $11: 30 \mathrm{JST}$. Convection around this cold front was active. The damage caused in the Fujisawa region by the wind gust recorded after 12:00 JST on April 20, 2006 was accompanied by a band of cumulonimbus clouds that had formed in the cold front. Figure 3 shows that line-shaped strong radar echoes with a width of 10 $\mathrm{km}$ and a top height of over $10 \mathrm{~km}$ observed over the Pacific Ocean. The strong echo corresponds to a precipitation intensity of over $30 \mathrm{mmh}^{-1}$.

\section{Surface damage and meteorological obser- vation data at Fujisawa}

In Fujisawa City, at approximately 12:05 JST on 20 April, 2006, a strong gust of wind occurred that caused damage in both Fujisawa City and the southwestern part of Yokohama City. Figure 4 is a damage map drawn up after a 2-day field survey, which shows the locations of damaged residential houses and nonresidential structures, such as wooden roofs, plastic greenhouses, and trees. Damage to over 40 residential and non-residential houses was observed, with the affected area covering $2 \mathrm{~km}$ by $50 \mathrm{~m}$. The damage rank 


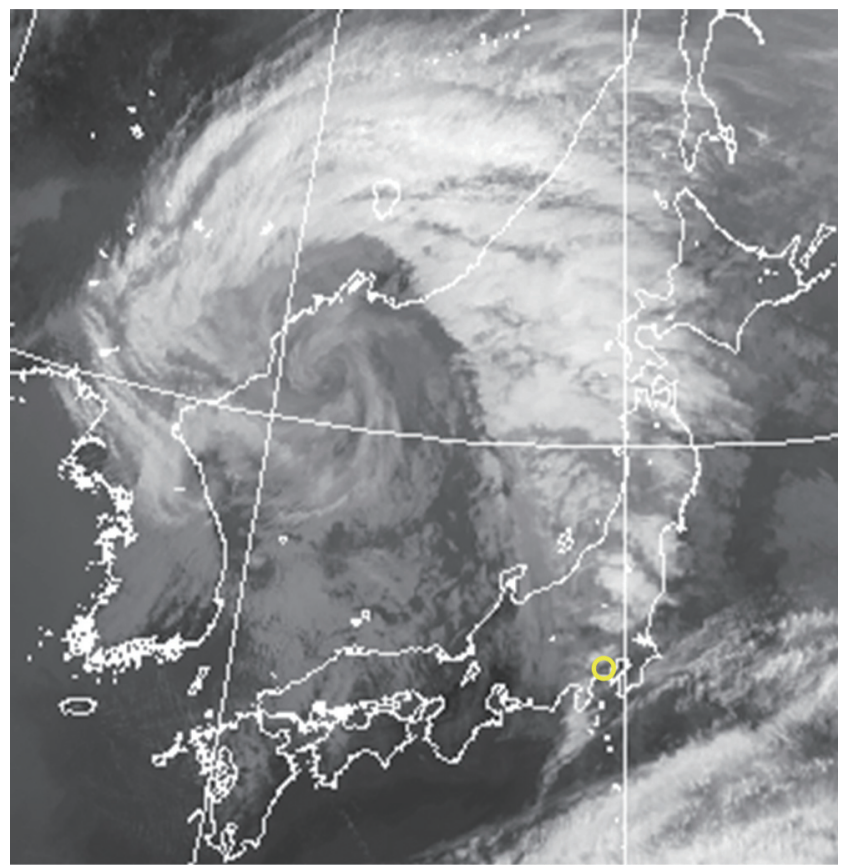

Fig. 2. GMS MTSAT-1R infrared image at $11: 30$ JST on April 20, 2006 (JMA). A circle denotes the location of Fujisawa City.

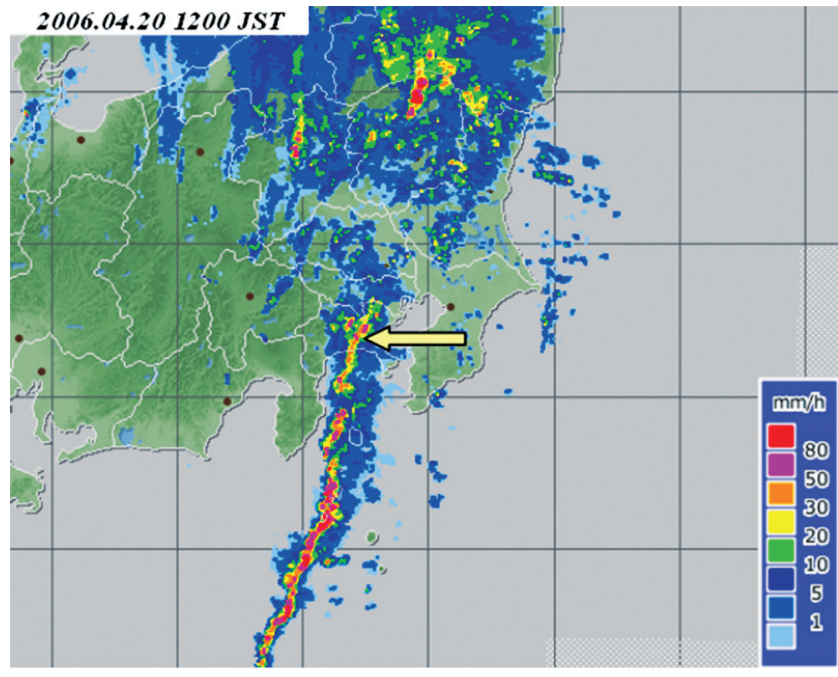

Fig. 3. Radar echo image at 12 : 00 JST on April 20, 2006 (JMA), taken from http://www.jma.go.jp/jp/radnowc/. An arrow denotes the location of Fujisawa City.

was estimated to be F0-P1-P1 on the Fujita-Pearsonscale (FPP-scale). F scale was determined by the features of overall damage. Distinct features of the damage included that: 1) the damage area was practically in a straight line, and 2) there were indications of cyclonic (rotary) winds, determined by tracing debris, flying debris and surveying surface damage patterns. These features suggested that the damage was caused by a tornado. Although there were many eyewitness accounts of the rotating wind of a "dust column" near the surface, there were no eyewitness accounts of a

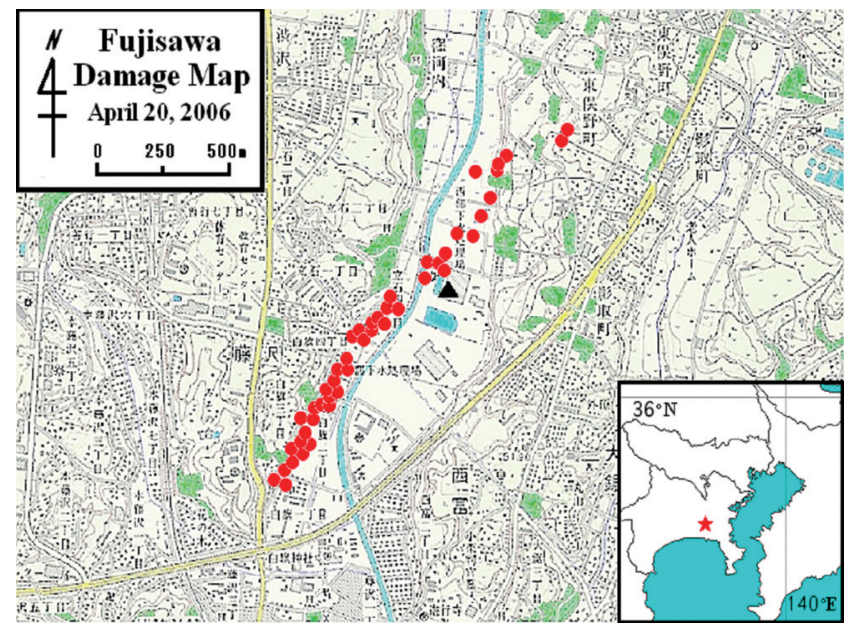

Fig. 4. Damage map of Fujisawa. A triangle denotes the location of the weather observation site. A star mark in the small square denotes the location of Fujisawa City.

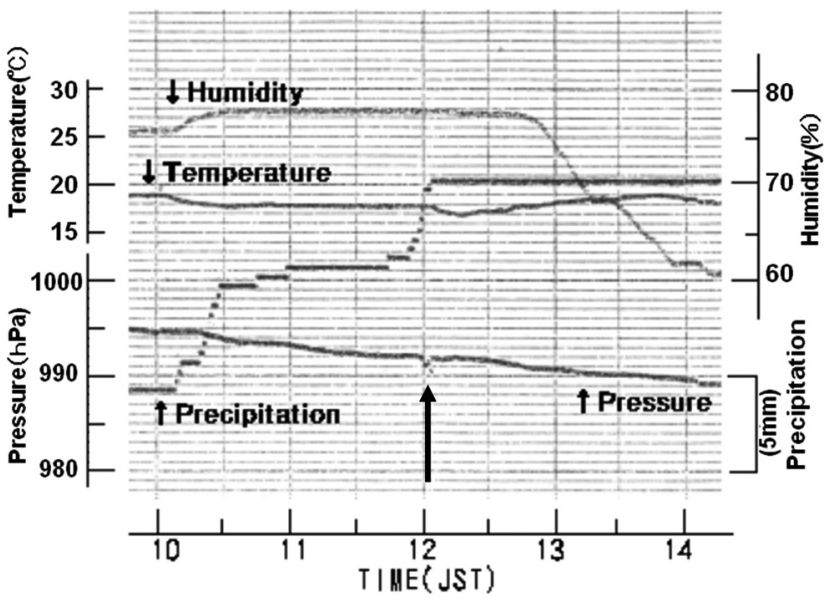

Fig. 5. Temporal changes in relative humidity, temperature, pressure and precipitation at the station near the damage area in Fujisawa City ( $\boldsymbol{\Delta}$ in Fig. 4) from 10:00 to 14:00 JST on April 20, 2006. A long arrow denotes the time of pressure drop.

funnel.

Figure 5 shows the change of each meteorological element with respect to time for the locations that were close to the damage area, as well as for locations $100 \mathrm{~m}$ east of the damage (shown as a triangle in Fig. 4). A pressure drop of $1.5 \mathrm{hPa}$ was recorded after 12:00 JST, indicating the passage of a tornado or its parent cloud (misocyclone). The tornado occurred at the passage of the cold frontal rainband.

\section{Doppler radar observation of parent cloud}

X-band Doppler radar (wavelength of $3 \mathrm{~cm}$ ) located at the Yokosuka, National Defense Academy $(100 \mathrm{~m}$ AGL), which will be referred to as the NDA radar, was used to acquire the radar echo reflectivity and Doppler velocity data. The range of the NDA radar was a circle with a radius of $64 \mathrm{~km}$. Plan position indicator (PPI) 


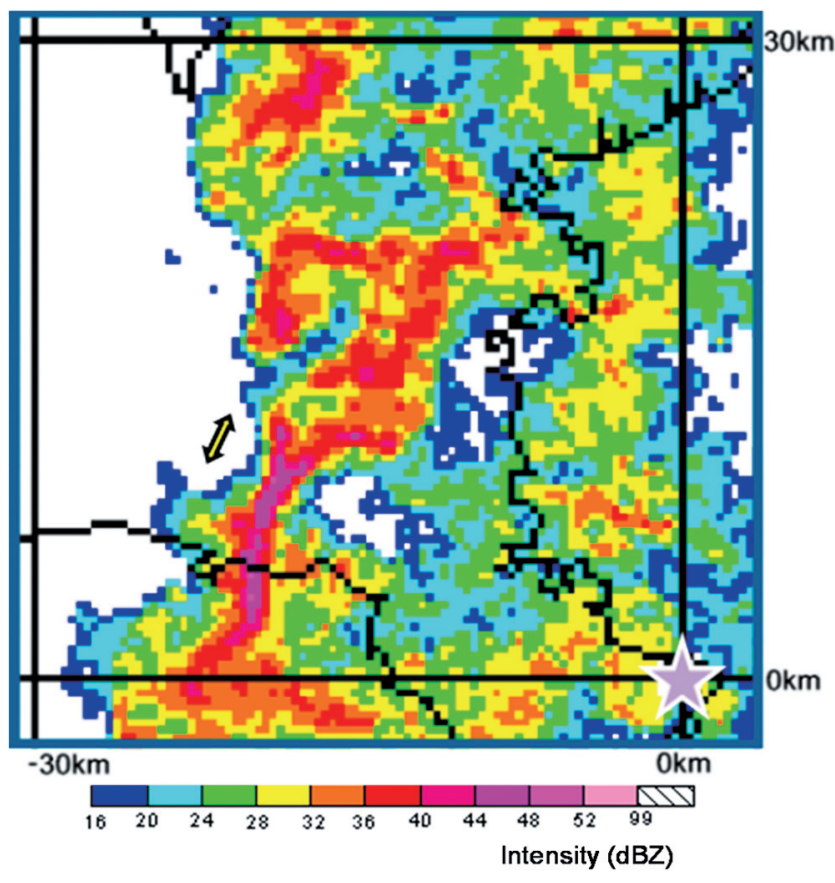

Fig. 6. CAPPI radar echo image (intensity) at $1 \mathrm{~km} \mathrm{AGL,}$ calculated from the 12:12 JST to $12: 18$ JST volume scan data, on April 20, 2006. The double arrow indicates the damage area, while the star indicates the location of the NDA radar.

volume scans of 20 steps, from an elevation (EL) of $0.5^{\circ}$ to $20.5^{\circ}$, and a range height indicator (RHI) scan, azimuth of $355^{\circ}$, were carried out at 8 minute intervals.

Figure 6 shows the NDA radar echo pattern (intensity) of the CAPPI (Constant Altitude PPI) at $1 \mathrm{~km} \mathrm{AGL,}$ calculated from 12:12 JST to $12: 18$ JST. A strong echo area greater than $36 \mathrm{dBZ}$ denotes the meandering line echo pattern. A hook-shaped (or ring-shaped) echo was observed northeast of the damage area. The diameter of the hook-shaped echo was about $5 \mathrm{~km}$. On the other hand, the tornado vortex signature was captured by the PPI volume scans from $12: 12$ JST $\left(E L=0.5^{\circ}\right)$ to $12: 15$ JST $\left(\mathrm{EL}=4.5^{\circ}\right)$. Figure 7 shows the Doppler velocity patterns at $12: 12 \mathrm{JST}\left(\mathrm{EL}=0.5^{\circ}\right.$, about $310 \mathrm{~m} \mathrm{AGL}$ at Fujisawa City) just after the generation of the tornado. The positive and negative opposite peak winds in the Doppler velocity, which were located about $3 \mathrm{~km}$ northeast of the damage area, indicate the presence of a circulation $2 \mathrm{~km}$ in diameter. These observations suggest the existence of a vertical oriented vortex tube, which implies that a misocyclone formed in the southwest quadrant of the hook-shaped echo.

Figure 8 summarizes the time-height section of the vorticity calculated from tornado vortex signatures. The vortex signature reached a height of $2 \mathrm{~km}$ (from $\mathrm{EL}=0.5^{\circ}$ to $\mathrm{EL}=4.5^{\circ}$ ). The vorticity, calculated by peak to peak Doppler velocity assuming axially symmetric vortex, was $4.9 \times 10^{-2} \mathrm{~s}^{-1}$ near the surface and decreased as the altitude increased. The lifetime of the misocyclone was the same as that of the surface tornado vortex (about 5 minutes of the dust column), as no vortex signature was observed in the next volume scan data of the Doppler radar once the tornado vortex signature had disappeared. The hook-shaped echo and the misocyclone, which were observed during one volume scan (from 12:12 JST to 12:18 JST), appeared just as the tornado touched down $(12: 05-12: 10 \mathrm{JST})$. In this
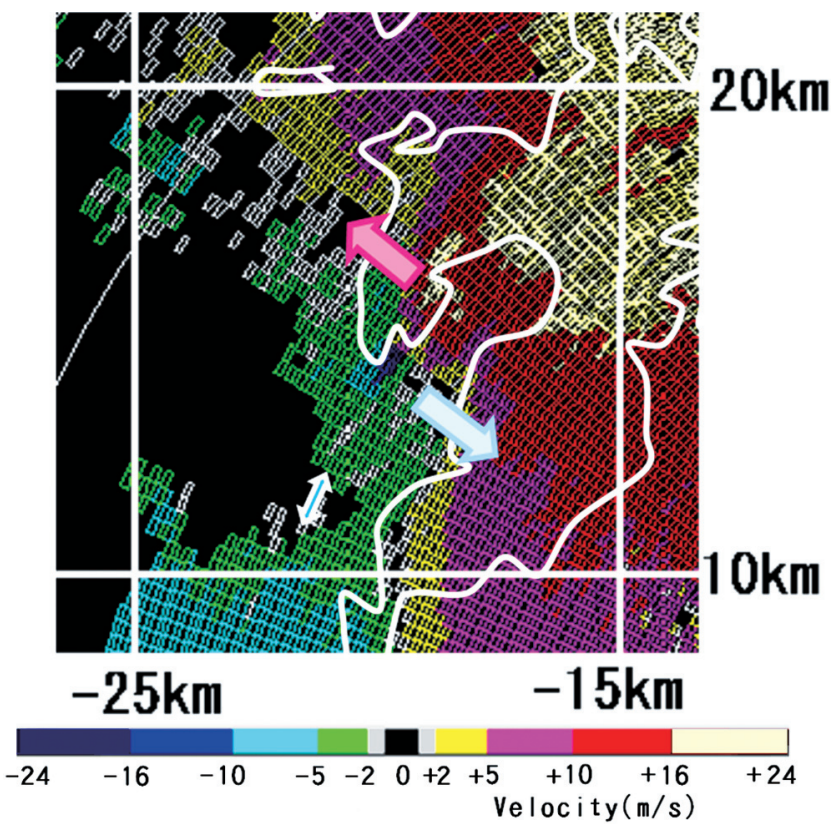

Fig. 7. Doppler velocity pattern of PPI $\left(E L=0.5^{\circ}\right)$ at 12 : 12 JST on 20 April, 2006. The parallel arrows indicate the position of the opposite peak Doppler velocity, which corresponds to the vortex signature (misocyclone). Solid lines denote the radar reflectivity of 32 $\mathrm{dBZ}$.

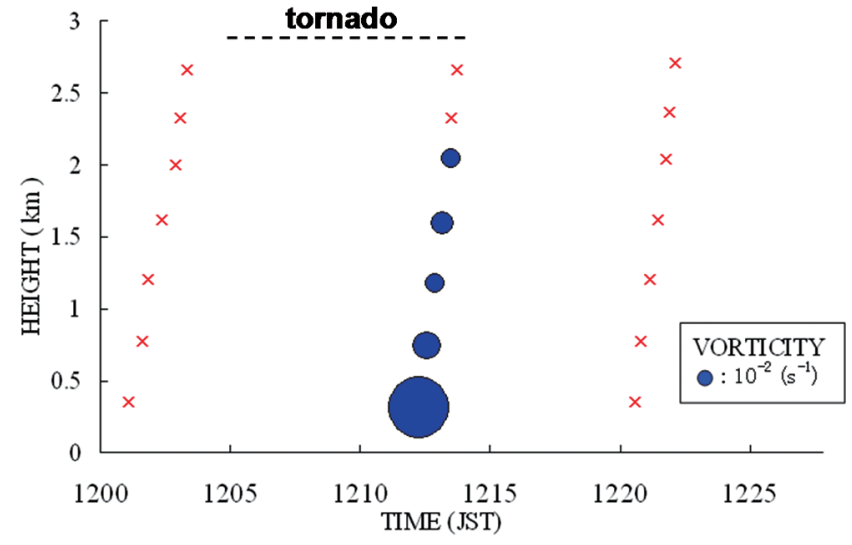

Fig. 8. The evolution of the vorticity (vortex signature) as a function of time. The solid circles show the order of the vorticity. $x$ denotes no vortex signature.

case, the tornado (surface dust column) and misocyclone would have formed simultaneously. The misocyclone, which had a diameter of $2 \mathrm{~km}$, lasted about 5 minutes. No mesocyclone was accompanied with the hookshaped echo, but a misocyclone was generated in the center of the hook-shaped echo.

\section{Summary and discussion}

At noon on April 20, 2006, a tornado occurred in Fujisawa City, Kanagawa Prefecture, Japan. The damage extended over an area $2 \mathrm{~km}$ by $50 \mathrm{~m}$ and had a 
rank of F0-P1-P1 on the FPP-scale. The tornado was accompanied with the passage of a cold front. The hookshaped radar echo $(5 \mathrm{~km}$ in diameter) was observed in the narrow cold frontal rainband. The Doppler velocity pattern indicates the existence of a misocyclone, which had a diameter of $2 \mathrm{~km}$ and a vorticity on the order of $10^{-2} \mathrm{~s}^{-1}$. The wind storm may have been caused by a nonsupercell tornado, which formed in the cold frontal wind shear zone.

Wakimoto and Wilson (1989) described a formation mechanism for non-supercell tornadoes that formed along the shear line in the vicinity of Denver, USA. In the present case, the horizontal wind shear in the narrow cold frontal rainband caused a vertical oriented vortex tube, which may have been stretched by the surface convergence. Strong convergence and stretching may occurred between updraft at the ground and cloud base.

Carbone (1982) pointed out the possibility of tornado generation in the frontal zone horizontal shear. Recently, Arnott et al. (2006) showed that misocyclones are associated with vertical velocity maxima in convergence along the cold front. Friedrich et al. (2005) discussed characteristics of misocyclones generated in the gust front and relationship between horizontal wind shear and convection initiation. However, few tornadoes generated in the narrow cold frontal rainband have been reported using Doppler radar. Further studies are needed in order to clarify the fine structure of narrow cold frontal rainband that causes tornadoes.

\section{Acknowledgments}

During the field investigation, residents affected by the wind storm, as well as other interested parties, provided us with valuable information. The authors wish to thank all of them for their help. The authors would also like to thank the Japan Meteorological Agency (JMA) and Yokohama City for providing the meteorological data. This observational study was supported by the $21^{\text {st }}$ COE Program: Wind Effects on Buildings and Urban Environment of the Tokyo Polytechnic University.

\section{Comments and supplements}

1. Photos of the damage at Fujisawa are shown in the Supplement 1.

\section{References}

Arnott, N. R., Y. P. Richardson, J. M. Wurman and E. M. Rasmussen, 2006: Relationship between a weakening cold front, misocyclones, and cloud development on 10 June 2002 during IHOP. Mon. Wea. Rev., 134, 311-335.

Carbone, R. E., 1982: A severe frontal rainband. Part I: Stormwide hydrodynamic structure. J. Atmos. Sci., 39, 258-279.

Friedrich, K., D. Kingsmill and C. R. Young, 2005: Misocyclone characteristics along Florida gust fronts during CaPE. Mon. Wea. Rev., 133, 3345-3367.

Kobayashi, F., O. Chiba and A. Matsumura, 1997: Morphology and structure of waterspouts occurred over Tosa bay on 4 October 1994. Tenki, 44, 19-34 (in Japanese with English abstract).

Kobayashi, F., K. Kikuchi and H. Uyeda, 1996: Life cycle of the Chitose tornado of September 22, 1988. J. Meteor. Soc. Japan, 74, 125-140.

Niino, H., O. Suzuki, H. Nirasawa, T. Fujitani, H. Ohno, I. Takayabu, N. Kinoshita and Y. Ogura, 1993: Tornadoes in Chiba prefecture on 11 December 1990. Mon. Wea. Rev., 121, 3001-3018.

Niino, H., T. Fujitani and N. Watanabe, 1997: A statistical study of tornadoes and waterspouts in Japan from 1961 to 1993. J. Climate, 10, 1730-1752.

Suzuki, O., H. Niino, H. Ohno and H. Nirasawa, 2000: Tornado producing mini supercells associated with Typhoon 9019. Mon. Wea. Rev., 128, 1868-1882.

Tokyo District Meteorological Observatory, 2006: On the gust damage in Fujisawa City, Kanagawa Prefecture on April 20, 2006 (in Japanese). Quick Report of Damage Investigation, Japan Meteorological Agency, (online), available from (http://www.tokyo-jma.go.jp/sub_index/ bosai/disaster/20060420/20060420.pdf), (accessed 2006$12-8)$.

Wakimoto, R. M., and J. W. Wilson, 1989: Non-supercell tornadoes. Mon. Wea. Rev., 117, 1113-1140.

Manuscript received 23 October 2006, accepted 9 January 2007

SOLA: http://www.jstage.jst.go.jp/browse/sola/ 